\title{
Comparing the Use of Forward-Looking and Contemporary Performance Measurement to Formulate Incentive Contracts in the Presence of the Horizon Problem: An Experimental Analysis
}

\author{
Luis Paulo Guimarães dos Santos \\ Universidade Federal da Bahià, Faculdade de Ciênicias Contábeis, Salvador, BA, Brazil \\ Received on 09.08.2014 - Desk acceptance on 09.09.2014- $2^{\text {th }}$ version approved on 01.27.2015
}

\begin{abstract}
This study compares the use of forward-looking and contemporary performance measurement in incentive contracts in the presence of the horizon problem. To do this, we used a single-factor experiment between pre- and post-treatment subjects, with a control group. The study had the participation of 76 undergraduate students, divided into 3 groups, and it registered that, when compared to the control group and the treatment group linked to contemporary performance measurement, the participants under the contract that rewarded having a forward-looking measurement as a basis acted more congruently with the long-term goal set for the experimental task. Consistent with predictions of the agency theory, the main finding of this research suggests that economic profit helps mitigating the problem of managerial myopia, indicating that incorporate it to contracts motivates agents to act more consistently with the company's long-term goals, even in the presence of the horizon problem. Besides, the study registered new evidence of the inadequacy of formulating incentive contracts having distorted performance measurements as a basis, such as book profit.
\end{abstract}

Keywords: incentive contracts, performance measurement, horizon problem. 


\section{INTRODUCTION}

The choice of performance measurement plays a key role in the formulation of incentive contracts, especially when the goal is motivating the behavior of managers for long-term actions when feeling the time within which they will remain employed is smaller than the company's optimal investment horizon. This situation, named in the literature as horizon problem, can induce a myopic behavior among these agents and compromise the company's ability to create value over time.

In the light of the economic theory, in the situation where the agent's job horizon is short-term, if her/his performance is rewarded having contemporary metrics as a basis, there will be an incongruity problem, leading her/him to act opportunistically, prioritizing actions that increase her/ his compensation in the short term at the expense of business' long-term performance. However, if the performance assessment metrics is congruent in order to align agent's interests to the principal's goals, even if the agent has a short-term horizon, she/he will have motivation to choose the effort level able to maximize the principal's utility, provided that this action also maximizes her/his compensation.

Many studies have suggested that using performance measurements based on contemporary accounting metrics can encourage a myopic behavior among managers, leading them to act in an incongruous way in face of the company's long-term goals and prioritize actions that improve their short-term pay (Narayanan, 1985; Gibbons \& Murphy, 1992; Farrell, Kadous, \& Towry, 2008). Empirical evidence indicates that there is a negative association between investments in long-term actions and incentive systems when the reward is tied to metrics related to contemporary book profit and managers have a short-term horizon (Dechow \& Sloan, 1991; Wunsch, 1992; Tyler, 1995; Cheng, 2004; Xu, 2009).

On the other hand, recent studies suggest that using performance measurements with a forward-looking nature ${ }^{1}$ helps mitigating the myopic behavior problem when individuals have a short-term job perspective (Dikolli, 2001; Cheng, 2004; Dikolli \& Vaysman, 2006; Huang, 2006; Farrell et al., 2008). Measurements with a forward-looking nature establish a strong link between managers' current decisions and future economic performance, increasing congruence between performance measurement and business' long-term goals (Dikolli, 2001; Dikolli \& Vaysman, 2006; Farrell et al., 2008; Berger, 2009) and their use in incentive contracts encourages the optimal allocation of efforts to contemporary actions that will increase company's profitability in the future (Dikolli, 2001; Sedatole, Kulp, \& Dikolli, 2003). Besides, some studies suggest that incorporating such metrics can play the roles of influencing and facilitating decision making, thus improving management performance (Farrell et al., 2008; Berger, 2009).

However, as pointed out by Farrell et al. (2008) and Matějka, Merchant and Van der Stede (2009), even with the existence of a large number of theoretical papers that address the way how to motivate agents having a horizon problem for long-term actions, there is little empirical evidence that give support to the benefits of using forward-looking performance measurement in incentive contracts for this purpose. Add to this the fact that a large part of the studies addressing the use of this type of performance measurement has given more emphasis to non-financial measurements.

To address this problem, this study seeks to broaden discussion on the theme and it experimentally compares the use of forward-looking performance measurement (based on the concept of economic profit) and contemporary performance measurement (based on the concept of net profit for the fiscal period) in the formulation of incentive contracts in the presence of the horizon problem.

Consistent with previous studies, the findings of this paper register that the forward-looking performance measurement motivated individuals to act more congruently with the long-term goal set and it led them to put more effort to fulfill the experimental task proposed. Besides, the experiment also identified that incentive based on contemporary performance measurement motivated a myopic behavior among the participants, who started acting with more interest in short-term results.

This study contributes to the literature in several ways, among which stand out: (i) studies addressing the use of forward-looking financial measurements in incentive contracts have predominantly focused on stock returns. We are not aware about the existence of other studies that experimentally address the use of economic profit expressed as net present value (NPV) in cash flows. Thus, the paper extends the literature on the subject by providing an empirical test to the existing theory by using a forward-looking performance measurement having a financial nature; (ii) generally, papers that address the use of economic profit in incentive contracts in the context of intertemporal decisions use residual profit. However, by nature, residual profit is a contemporary metrics, because it adjusts book profit for the period by deducting the weighted average cost of capital, regardless of the NPV of the future benefit flow, significantly differing from the concept of economic profit that derives from the economic theory. This paper extends the existing literature because it uses ex-ante economic profit, which is by nature a forward-looking metrics; (iii) there are few experimental investigations addressing the use of forward-looking performance measurements in incentive contracts in the presence of the horizon problem. Such studies, if properly designed, are significant because they provide a causality test to the existing knowledge. In this way, this research advances when compared to previous papers, because, as far as it is known, it is among the first ones using an experimental design like pre-test type, post-test with a control 
group, making its results more robust when compared to those of previous studies; (iv) given that the results of studies on the effect of monetary incentive and its role to motivate an increased effort and an improved performance on tasks still not complete, the findings of this study help expanding evidence in favor of the hypothesis that monetary incentive matters.

\section{BACKGROUND AND HYPOTHESES}

\subsection{The problem of the horizon and incentive contracts based on contemporary performance measurements.}

In many situations, employees may have to allocate efforts to actions that take effect on the short or long term. When the agent has a preference for actions that have an effect on the short term at the expense of generating long-term results, it is claimed that her/his behavior is myopic (managerial myopia). According to $\mathrm{Xu}$ (2009), problems related to myopia lead to actions that improve performance in the short term, but destroy the company's value in the long run. This dysfunctional behavior represents a tradeoff between allocation of effort to actions the employee is interested in and to actions the company is interested in, and this is a particular way of expressing the congruence problem that may be related to performance measurement.

The time horizon problem in the job has been regarded as a relevant source for managers' myopic behavior. As explained by $\mathrm{Xu}$ (2009), when the manager's time perspective in the job is different from the company's optimal investment horizon, she/he may wish to make her/his performance look more valuable in the short term, even at the expense of maximizing the company's value in the long run. The horizon problem emerges because the company has a long and indefinite service life, while the manager's horizon depends on the period within which she/he holds the job.

According to Dikolli and Vaysman (2006), an agent may have a short-term horizon in the job for several reasons. For instance, she/he may be close to retirement or, simply, be averse to defer compensation. There may be little loyalty to the organization where she/he works, wishing to leave the company in search of better opportunities. Even being loyal, if there is a career development program, the agent may be waiting to move to another division of the company and she/he does not expect to benefit from the future consequences of current actions.

According to Narayanan (1985), the time horizon in the job influences on the short-term bias of employees. According to the author, the higher the contract time, the lower probability these agents choose projects with faster compensations that are suboptimal from the viewpoint of the business' investment decisions. Hypothetically, the horizon problem is a major threat to the creation of value, because the employee on the verge of leaving her/his posi-
Along with this introduction, the paper consists in 5 sections. Section 2 summarizes the main spectra of the literature addressing the theme and the hypotheses proposed. Section 3 provides a description of the methodology, as well as the experimental design and statistical procedures used to test the hypotheses. Section 4 presents the study results. Finally, section 5 presents the conclusions. tion has no incentive to engage in actions that are aligned with the company's long-term interests.

The consequences deriving from the horizon problem can be exacerbated when employees are encouraged having contemporary accounting metrics as a basis. Feltham and Xie (1994) argue that using contemporary book profit as a performance measurement is criticized because it does not fully reflect the economic consequences of employees' actions. According to the authors, book profit is short-term in orientation and it ignores the future benefits of each activity developed by the company. According to Huang (2006), evidence registered in the literature has pointed out that contracts linked to contemporary performance measurements linked to book profit may induce managers to behave myopically in order to increase their pay, sacrificing the creation of long-term value for the company. This becomes more dramatic when the agent has a short-term horizon in the job, because there are increased chances that the manager gives up on projects having more positive NPV, but having smaller contemporary book profits in favor of projects with lower or negative NPV.

Dechow and Sloan (1991) investigated a sample of chief executive officers (CEOs) and they found evidence of the congruence problem between the managers' horizon and the company's. The authors registered that, when executives are in their last years in office, they spend less on research and development (R \& D) for new products. Also in this trend, Naveen (2006) registered that CEOs reduce spending on $\mathrm{R} \& \mathrm{D}$ over their time in office. The study identified a negative correlation between time in office and expenditure on R \& D.

Wunsch (1992) also tested the hypothesis that long-term investments are negatively related to short-term incentive contracts when there is the horizon problem. The study conducted by this author registered that the relation between CEO's age and investment on long-term expenditure was initially positive, but when the executive reached an age of about 58 , this relation became negative. In this way, Barker and Mueller (2002) found evidence that this spending was higher in companies where the CEOs were younger and had part of their wealth invested in company stock.

$\mathrm{Xu}$ (2009) also found evidence that companies with short-term contracts underinvest, while those that kept longer horizon contracts invested more in capital expenditures and $\mathrm{R} \& \mathrm{D}$. 
Collectively, the empirical studies mentioned above suggest that using performance measurements linked to contemporary accounting metrics to formulate incentive contracts contingent on performance, when the agent believes she/he will stay in the job for a short time, might lead to managerial myopia, making her/him to allocate less effort in contemporary actions that maximize the company's NPV.

\subsection{The use of forward-looking performance measurements for contractual purposes.}

The formulation of incentive contracts that supplement the book profit with other measurements that take into account the future consequences of contemporary actions of agents is among the mechanisms discussed in the literature to deal with the short-term view of managers. Dikolli and Vaysman (2006) explain that there are two possibilities to provide managers with incentives to allocate effort to long-term actions: compensate them based on forward-looking performance measurements or based on stock returns.

According to Dikolli (2001), forward-looking performance measurements are metrics that reflect drivers of the company's future performance and they are used to adjust the future investment returns with the costs generated by the current investment, therefore, they serve to the purpose of mitigating dysfunctional behavior of managers in relation to myopic decisions on resource allocation.

When the time horizon in the agent's job is short-term, Dikolli (2001) argues that the use of forward-looking measurements in contracts, when compared to conventional rewards ruled by contemporary financial performance, may be a more cost-effective and timely way to encourage efforts through actions that take into account the company's future performance and it helps mitigating agent's engagement problem in myopic behavior, because it may induce a more effective allocation of effort to activities with short-term and long-term effects. The author explicitly assumes that the importance attached to the forward-looking measurements depends on the agent's time horizon and analytically demonstrates that the judicious use of these performance measurements in incentive contracts can influence the employees' effort allocation decisions to fulfill tasks. According to the theoretical model proposed by Dikolli (2001), employees with a short-term horizon will allocate more effort to actions that increase the company's future performance if they are encouraged having contracts that include forward-looking performance measurements as a basis.

Farrell et al. (2008) found evidence that the effect of including forward-looking measurements in incentive contracts depends on the employee's time horizon. The authors conducted an experiment in which they compare the effort on long-term actions among employees with a short-time horizon and those who had a long-term horizon, under two types of contracts: forward-looking or contemporary. The results clearly indicated that the use of a forward-looking contract, as opposed to a contemporary contract, had greater effect on long-term efforts among employees with a short-term horizon in the job.

\subsection{Hypotheses.}

To investigate how the use of forward-looking and contemporary performance measurements in contracts motivates individuals to act more consistently with long-term goals, in the presence of the horizon problem, an experiment was conducted having as a basis a simulation where the participants are contracted to fulfill the task of allocating resources in contemporary actions, in order to maximize the NPV in future cash flows of a company. In the experiment proposed, the following agency problem was emulated: under a certain type of incentive contract, the agent must decide whether she/ he allocates more resources to try maximizing the NPV in future cash flows of the company, reducing her/his compensation based on a contemporary performance measurement, or she/he decreases investment in long-term actions to try maximizing her/his reward.

As noticed, empirical evidence suggests that in the situation where the agent has a short-term horizon in the job, if her/his performance is rewarded having contemporary metrics as a basis, there will be an incongruity problem leading to inadequate investment decisions, because the agent will act opportunistically, prioritizing actions that increase her/his remuneration in the short term at the expense of long-term performance of the company. In the context of the experiment conducted, this implies that agents rewarded having a contemporary performance measurement as a basis will allocate fewer resources in actions that affect the company's future performance, giving preference to increased contemporary performance measurement and, as a consequence, their reward. Based on this, the following hypothesis may be formulated on the economic behavior of the experiment subjects:

- H1 - Investment of resources in contemporary actions that maximize the net present value in future cash flows of the company will decrease when individuals are encouraged through contracts linked to contemporary performance measurement.

On the other hand, as suggested by some analytical and empirical studies, forward-looking performance measurements influence on the decision to allocate effort to long-term actions that create value for the company when there is the horizon problem. So, it is expected that incentive systems based on performance measurements having a forward-looking nature encourage individuals to act more congruently with business' long-term goals, even when they have a short-term horizon. Therefore, it is possible to formulate the following hypothesis about the experiment:

- H2 - Investment of resources in contemporary actions that maximize the net present value in future cash flows of the company will increase when individuals are encouraged through contracts linked to forward-looking performance measurement. 


\subsection{Experiment description and internal validity.}

In the experiment, the participants play the role of store manager in a retail chain specialized in reprography services and they have the sole task of maximizing the NPV in cash flows expected from the store. Therefore, they must allocate in an optimal way a fixed budget to two activities regarded as key to the success of the company. The application of resources into these activities affects both net profit for the period and the NPV in future cash flows. The activities are named this way: Activity I - Customer Service; and Activity II - Recruitment, Selection, Training, and Personnel Qualification. To fulfill the task, each participant uses a simulator that helps analyzing which is the optimal combination of investment in the two activities.

Similarly to the strategy adopted by Kelly (2007) and Berger (2009), the subject must allocate a fixed budget of 30,000 Lira (currency in the experiment) between the two activities following this rule: (i) investment amounts should be multiples of 1,000; and (ii) the participant can allocate any value between 1,000 and 29,000 Lira to each activity. At least 1,000 Lira should be invested in each activity. Before starting simulation, instructions on the use of the software used in the experiment were provided. Soon after, the participant had access to a computer screen with the full description of these activities and how they would impact the current and future performance of the store, as well as the details of the task she/ he should fulfill. In addition, it was informed that the prediction of net cash flow for the coming periods is a function of costs incurred for the current period and that such expenses reduce the net book profit of the store for the current period. On the other hand, the higher the net cash flow predicted for the coming periods, the higher the net book profit for the coming periods. Therefore, the participant should understand that the net profit for the period also depends on the expenses incurred by managers for previous periods.

In this experimental context, the agency conflict is characterized by the tradeoff the participant faces between allocating more effort to try finding the optimal combination of investments that maximizes future cash flow of the store or avoid the task by investing as little as possible (1,000 Lira) in each activity. Thus, in the experiment, allocating resources to the activities I and II means that the subject is committed to long-term performance. On the other hand, failing to allocate resources denotes a lack of commitment to long-term actions.
The amount invested in each activity does not have a strictly linear effect on the future net cash flow. From a certain level of resource allocation to each activity, the marginal effect on cash flow is decreasing. With this configuration, the participant might have to assess which is the optimal investment level that will maximize the net cash flow of the store and deal with the problem of avoiding allocating resources that generate negative NPV (overinvestment) or lose investment opportunity (underinvestment).

For each period, the non-linear effect of the investment on the net cash flow and net profit is different (there is a different mathematical function for each store/ period $^{2}$ ). This ensures that there is no memory effect due to the learning process with simulation to choose the optimal investment level.

At the beginning of the experimental session, it was informed that under no circumstances the manager would remain over a period (fiscal year) in the same store. Necessarily, for each distinct period, she/he would work in a different store. This feature of the experiment is what determines the horizon problem, because, in this case, the participant will not be in the current store to "take advantage" of the future benefits generated by her/ his investment decision. Besides, preventing the subject to think that her/his continuity in the experiment necessarily depends on her/his ability to identify the optimal investment level, it was explained that the participants would remain for ten periods in the company, regardless of her/his performance as a manager in the stores.

The experiment was structured into 3 stages: phase (i) training - consisting of 2 stores; phase (ii) fulfilling the task before implementing the incentive system - consisting of 5 stores; and phase (iii) fulfilling the task after implementing the incentive system - involving over 5 stores. At the second phase, all participants received a fixed remuneration of 1,500 Lira per store/period. Each 1,500 Lira are equal to $\mathrm{R} \$ 1.00$.

At the third phase of the experiment, when the participant was subject to the incentive system based on a contemporary performance measurement (named as net profit in the fiscal year), she/he received a bonus of $5.85 \%$ over this performance measurement. On the other hand, when she/he was subordinate to the incentive system based on a forward-looking performance measurement (named economic profit), the participant received a bonus of $4.5 \%$ over the estimated economic profit. Additionally, there was a control group that received fixed salary in stages (ii) and (iii) without added bonus. Box 1 summarizes the information on incentive contracts made available to the participants.

After the training phase, in the stores/periods from 1 to 5 , mathematical functions are effectively different. However, these same functions repeat again in the stores/periods from 6 to 10 , in a different order. This feature ensures that the experiment optimal investment levels are equal before and after the experimental manipulation. This means that, if the participant identifies the optimal investment point in all stores, the sum and the average value of investments in the activities I and II in the stores/periods from 1 to 5 will be equal to the sum and average value of investments in stores/periods from 6 to 10 . The values allocated to the activities I and II that maximize the NPV in the stores are: $(\$ 12,000$ and $\$ 14,000) ;(\$ 16,000$ and $\$ 5,000) ;(\$ 9,000$ and $\$ 21,000) ;(\$ 12,000$ and $\$ 16,000) ;$ and $(\$ 7,000$ and $\$ 19,000)$. 


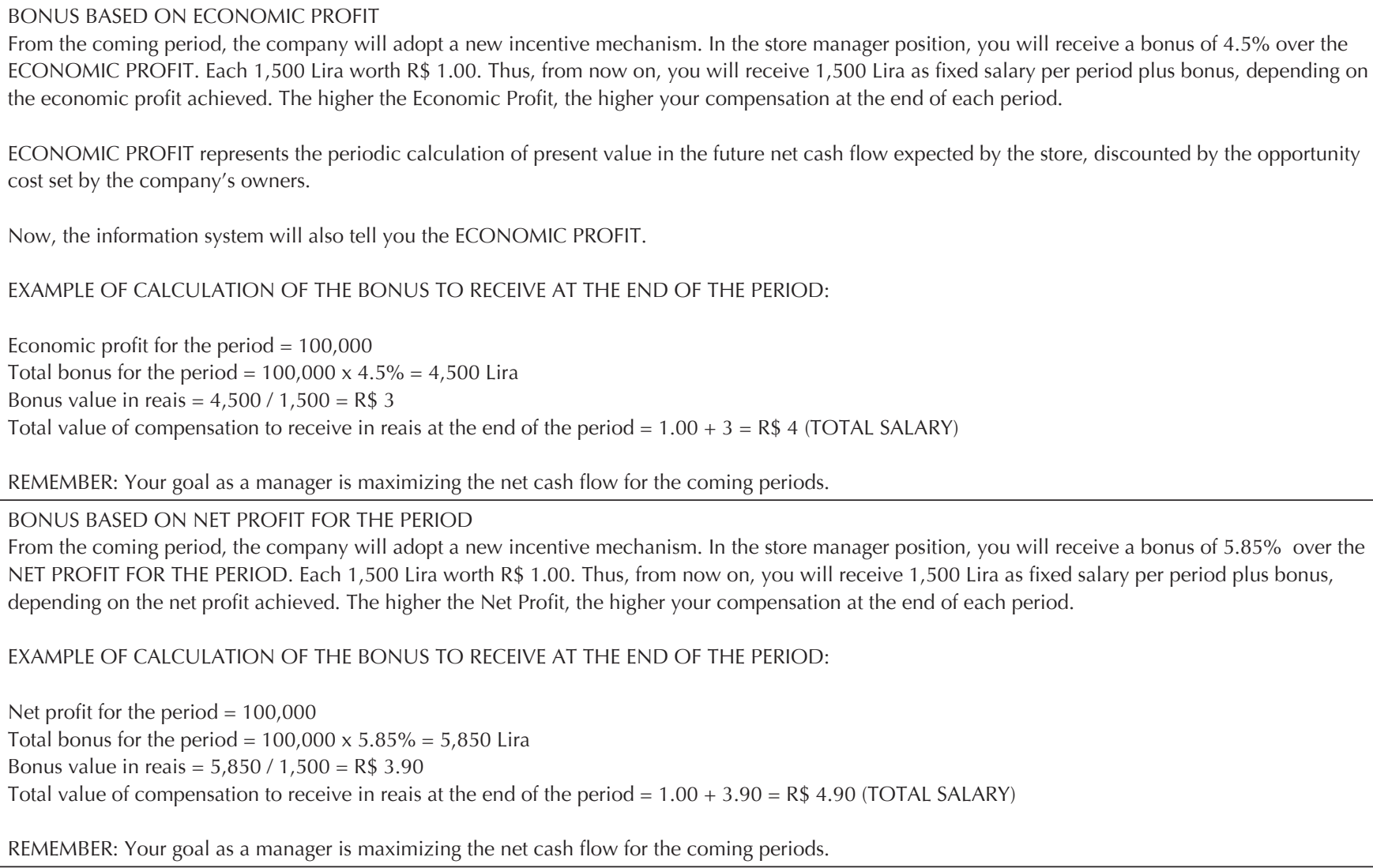

In the experiment, the economic profit ${ }^{3}$ corresponds to the variation in the NPV of future cash flows expected by the store. The discount rate (opportunity cost) was $15 \%$. In turn, net income for the fiscal year represents the difference between revenues and costs measured in historical terms. The predicted economic profit and net profit for the period is automatically informed to all participants every time they simulate their investment decisions. In turn, at phase (iii), in the case of the participants linked to bonus having book profit as a basis, the net profit for the period actually realized is informed at the time of validating investment decision along with the bonus value. In the calculation of this profit, there is a random component so that it is always different from the prediction made at the simulation phase.

To ensure the internal validity of the experiment, we used a single factor design among subjects, pre- and post-treatment, with a control group. In this design, the selection bias is controlled by random assignment of subjects to the groups. The incentive contract, divided into two types (economic profit - representing the forward-looking measurement; and book profit - representing contemporary measurement) is the only factor or independent variable of the experiment. The factor was operationalized through dummy variables.

\subsection{Dependent variable.}

The dependent variable of the experiment is the investment value in activities I and II, representing the action of the participants in face of the long-term goal, encoded as Invest. In turn, the type of contract is the independent variable.

\subsection{Control condition.}

First, the subjects were randomly assigned to three groups: 1 control and 2 experimental. During the first 5 periods, all participants, regardless of the group, receive only a fixed salary of 1,500 Lira (or R \$ 1.00) per period.

From the sixth period on (excluding the two training periods), the experimental groups start receiving an additional variable monetary incentive based on performance (measured or through the book net profit or economic profit). At this stage, the control group keeps receiving a fixed salary. In addition, the participants who belonged to the control group received an additional compensation of $\mathrm{R} \$ 5.00$ for collaboration in the experiment, but they only became aware of this additive at the time of receiving the final pay.

\subsection{Pre-test.}

The experiment was pre-tested before being applied in its final form. This procedure took place in an experimental session held one month before the final data collection. At this stage, 20 subjects participated in accordance with the following composition: 8 in the group under the incentive contract based on book income; 6 in 
the group under the contract linked to economic profit; and 6 in the fixed salary group.

\subsection{Procedures for conducting experimental sessions.}

The experiment was administered in its final form in three sessions. The application procedure followed this protocol:

1.Participants were invited by email to participate in the experiment.

2.Participants signed up through a message form on the Internet.

3. Based on online registration, participants were randomly assigned to the 3 groups -2 experimental and 1 control.

4. On the day of experiment application, students came to the computer laboratory, they identified themselves and were assigned to the laboratory sector, which accommodated the machines configured according to the group to which they belonged.

5. Once all the students were already accommodated in their respective places, the last check was made to see whether they were all in the group to which they had been drawn.

6. The session coordinator explained the experiment nature, read all instructions needed to fulfill the task and answered to the questions that emerged.

7. At the end of the session, participants were instructed to look for the session coordinator to get paid for their participation.

\subsection{Subjects.}

The study had the participation of students regularly enrolled in undergraduate courses in Accounting Sciences, Administration, and Economics of the University of São Paulo and students of Accounting Sciences of the Federal University of Bahia. Students were selected in these two institutions primarily due to convenience and ease of access to them. The selection of undergraduate students was based on the premise that they have a relative ease to grasp the requirements of the task assigned to the simulation, due to familiarity with some concepts of economics, accounting, finance, and business management.

The participation of undergraduate students is consistent with other experimental studies in accounting involving incentive contracts (Chow, 1983; Schotter \& Weigelt, 1992; Mauldin, 1997; Sprinkle, 2000; Kelly, 2007; Farrell et al., 2008; Berger, 2009; Denison, Farrell, \& Jackson, 2012). Besides, the participation of students is timely because they do not have many preconceived ideas about an appropriate contract type and the incentive level offered in this experiment tends to be more meaningful to them (Mauldin, 1997).

\subsection{Procedure for testing the hypotheses.}

The testing of hypotheses was done by using multiple regression analysis based on the difference in differences method, considering the following general model:

Invest $=\beta_{0}+\beta_{1}(\mathrm{Dt})+\beta_{2}(\mathrm{Eco})+\beta_{3}($ Book $)+\beta_{4}\left(\mathrm{Eco}{ }^{*} \mathrm{Dt}\right)$ $-\beta_{5}\left(\right.$ Book $\left.^{\star} \mathrm{Dt}\right)+\varepsilon_{\mathrm{i}}$

Where:

a) Invest is the dependent variable of the model and it represents the amount of investment made by individuals when fulfilling the task proposal.

b) $\beta$ s are the model parameters, where $\beta_{0}$ represents the expected value of the variable under study when analyzing the control group before treatment, $\beta_{1}$ indicates how the variable under study behaves after experimental manipulation and it measures the difference (before and after) within the control group, $\beta_{2}$ measures the marginal effect of belonging to the treatment group under economic profit before experimental manipulation, $\beta_{3}$ measures the marginal effect of belonging to the treatment group under book profit before the experimental measurement, $\beta_{4}$ and $\beta_{5}$ represent the difference in differences (difference within the control group minus the difference within the treatment groups) and they measure the treatment effect on the variables under study.

c) $\varepsilon_{\mathrm{i}}$ is the model's error term; and

d) $D t$ is a dummy variable, which will be 1 when data refer to post-treatment and 0 when data refer to the pre-treatment period.

e) Eco and Book are dummy variables that represent the impact of belonging to the treatment groups linked to economic profit or net profit, respectively. They will be equal to 1 when the subject is in a treatment group and 0 in other situations.

\section{RESULTS: ANALYSIS AND DISCUSSION}

\subsection{Demographic data.}

In total, 90 students participated in the experiment. However, the final sample consisted of only 76 subjects, out of which $58 \%$ were men and $42 \%$ women. Most were students of Accounting Sciences (66), 4 studied Economics, 4 were students of Administration, and 2 were studying International Relations. On average, the participants were 22 years old, $51 \%$ said they were working or doing an internship and $49 \%$ said that, at the time, they were only studying. Participants received, on average, $\mathrm{R} \$ 16.52$. However, the lowest 
price paid was $\mathrm{R} \$ 12.00$ and the highest was $\mathrm{R} \$ 20.00$. In addition to the 90 students who participated in the regular experimental sessions, other 20 took part in the pre-test of the experiment, but demographic information on this group is not provided by this paper.

\subsection{Pre- and post-experimental assessment of groups.}

Out of the 76 participants who made up the final sample after random distribution, 25 belonged to the treatment group linked to book profit (Treatment 1), 25 to the treatment group linked to economic profit (Treatment 2), and 26 to the control group. At the first phase of the experiment (training), the participants answered to a questionnaire, in order to assess their knowledge on the main simulation features. At this stage, all subjects in the final sample answered correctly to the four questions proposed. No divergence was identified between the groups.

Participants answered to the post-experimental questionnaire, which contained two control questions to check their opinion about the reality and difficulty of the simulation. This checking was made through the following propositions: (i) "I think this simulation is quite realistic"; and (ii) "How hard do you think fulfilling the task of investing in the two activities is?"

The answers were collected by using a Likert scale, ranging from 1 to 7 . In the first utterance, I totally disagree is equal to 1 and $I$ totally agree is equal to 7 . In the second, Very easy is equal to 1 and Very difficult is equal to 7. Table 1 displays the descriptive statistics of answers obtained from all participants per group.

Table 1 Descriptive statistics of post-experimental questions per group

\begin{tabular}{|c|c|c|c|c|c|c|}
\hline Propositions & Groups & $\mathbf{N}$ & Average & Standard deviation & Minimum & Maximum \\
\hline \multirow{3}{*}{ Reality } & Book & 25 & 4.32 & 1.41 & 1 & 6 \\
\hline & Economic & 25 & 4.16 & 1.46 & 1 & 7 \\
\hline & Control & 26 & 4.31 & 1.32 & 2 & 7 \\
\hline \multirow{3}{*}{ Difficulty } & Book & 25 & 3.84 & 1.52 & 1 & 6 \\
\hline & Economic & 25 & 4.48 & 1.42 & 1 & 7 \\
\hline & Control & 26 & 4.08 & 1.16 & 2 & 6 \\
\hline
\end{tabular}

Source: Prepared by the author.

Table 1 shows that the average values and standard deviations of the groups are very close, suggesting there is homogeneity. To check whether there is a statistically significant difference between them, we applied a va- riance analysis test (one-way ANOVA) and a non-parametric equivalent - Kruskal-Wallis H-test (ANOVA on orders). Tables 2 and 3 register the results of their respective procedures.

Table 2

One-way ANOVA results for post-experiment questions

\begin{tabular}{|c|c|c|c|c|c|c|}
\hline & & Sum of squares & Freedom degrees & Average squares & $\mathbf{F}$ & $P$ value \\
\hline \multirow{3}{*}{ Reality } & Between groups & 0.40 & 2.00 & 0.20 & 0.10 & 0.90 \\
\hline & Within groups & 142.34 & 73.00 & 1.95 & & \\
\hline & Total & 142.74 & 75.00 & & & \\
\hline \multirow{3}{*}{ Difficulty } & Between groups & 5.24 & 2.00 & 2.62 & 1.39 & 0.26 \\
\hline & Within groups & 137.45 & 73.00 & 1.88 & & \\
\hline & Total & 142.68 & 75.00 & & & \\
\hline
\end{tabular}

Source: Prepared by the author.

\begin{tabular}{lcc}
\hline & Reality & Difficulty \\
\hline Chi-square & 0.41 & 2.75 \\
Freedom degrees & 2.00 & 2.00 \\
P value & 0.81 & 0.25 \\
\hline
\end{tabular}

Source: Prepared by the author. 
Statistical tests converge to the same result ( $\mathrm{p}$ values of $\mathrm{F}$ statistics and chi-square in each of the questions above the 0.05 significance level), suggesting there is no statistical difference between the groups. These results indicate that the procedure of randomly assigning subjects to the treatment and control groups maintained homogeneity between them and that, perhaps, experimental manipulation did not change participants' perception of the aspects assessed. However, a more robust assessment would require a comparison of the answers before and after experimental manipulation, and this has not been done.

\subsection{Hypothesis testing.}

Since data was collected for various participants/units at 10 different periods (longitudinal data - set of observations in the same units at various times), we applied the multiple regression analysis technique to panel data ${ }^{4}$. Hypothesis testing was based on statistical analysis of coefficients of the variables $\boldsymbol{B} \boldsymbol{o o} \boldsymbol{k}^{\star} \boldsymbol{D} \boldsymbol{t}(\mathrm{H} 1)$ and $\boldsymbol{E} \boldsymbol{c o}{ }^{\star} \boldsymbol{D} \boldsymbol{t}(\mathrm{H} 2)$, having the constant $\beta_{0}$ as the analysis reference, because it represents the control group before treatment. Tables 4,5 , and Figure 1 show the summary of results.

Table 4 Summary of the average investments per period/store

\begin{tabular}{|c|c|c|c|c|c|c|}
\hline \multirow{2}{*}{ VARIABLES } & \multicolumn{2}{|c|}{ BOOK } & \multicolumn{2}{|c|}{ ECON } & \multicolumn{2}{|c|}{ FIXED } \\
\hline & Before & After & Before & After & Before & After \\
\hline Invest & $24,544.00$ & $21,792.00$ & $22,968.00$ & $27,648.00$ & $22,230.77$ & $23,600.00$ \\
\hline
\end{tabular}

Note: Invest represents the average investment value, per store, in the activities I and II.

Source: Prepared by the author.

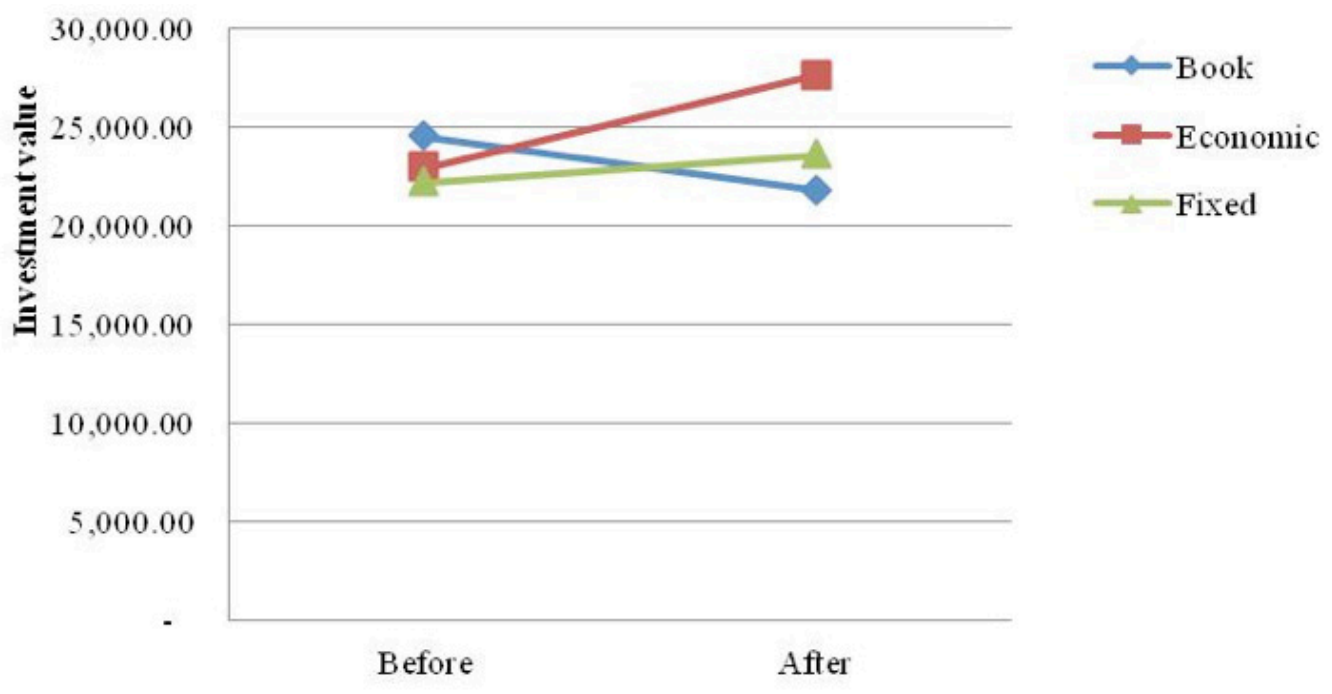

Source: Prepared by the author.

Figure 1 Investment value before and after treatment.

Table 5 Regression results in panel data for the variable Invest

\begin{tabular}{lcccc}
\hline & Coefficient & Standard error & T-ratio & P value \\
\hline Const & $22,230.8$ & 868.638 & 25.5927 & $<0.00001$ \\
Dt & $1,369.23$ & $1,228.44$ & 1.1146 & 0.26537 \\
Book & $2,313.23$ & 353.221 & 6.5490 & $<0.00001$ \\
Eco & 737.231 & 346.583 & 2.1271 & 0.03373 \\
Book* Dt & $-4,121.23$ & 499.53 & -8.2502 & $<0.00001$ \\
Eco* Dt & $3,310.77$ & 490.142 & 6.7547 & $* *$ \\
\hline
\end{tabular}

Notes: (i) ** significant at $5 \%$; ** significant at $1 \%$; (ii) panel data with random effects (GLS); (iii) the intercept (constant) reflects the measurement of the variable under study for the control group before treatment; (iv) $D t$ is a dummy variable that takes value 1 when the data refer to the post-treatment period and 0 for the pre-treatment period. It represents the marginal value of the variable under study for the control group after treatment; $(v) B o o k^{*} D t$ indicates the treatment effect when net profit is the performance measurement; $E C O^{*} D t$ indicates the treatment effect when economic profit is the performance measurement; (vi) the dependent variable Invest represents the average investment value, per store, in the activities I and II; (vii) F statistics $(5.754)=11.21$ with $p$ value $=0.000$; and $($ viii $) \mathrm{R}^{2}=0.0692$.

Source: Prepared by the author.

The choice of hypothesis testing by regression analysis with panel data was based on the following advantages provided by the model, according to Cameron and Trivedi (2005): (i) regression with panel data provides greater precision and effectiveness to estimates as a result of the increased number of observations derived from combining or grouping several time periods of data for each individual; and (ii) panel data allow learning more about the dynamics of individual behavior, something which can be critical to understand a certain phenomena. 
Data from tables 4 and 5 show that the incentive contingent on performance influenced the behavior of individuals, regardless of the contract, because betas in the variables $\boldsymbol{E} \boldsymbol{c o}{ }^{\star} \boldsymbol{D t}$ and $\boldsymbol{B o o k}^{\star} \boldsymbol{D} \boldsymbol{t}$ are statistically significant $(3,310.77$ with $\mathrm{p}$ value $=0.0000$ and $-4,121.23$ with $\mathrm{p}$ value $=0.0000$, respectively). This suggests that monetary incentive encouraged the participants to increase performance measurement and, as a consequence, the reward. As Table 5 shows, the coefficient sign for the variable $\boldsymbol{B o o k}^{\star}{ }^{\boldsymbol{D} t}$ is negative, indicating that, unlike the group linked to economic profit, the participants encouraged having book profit for the period as a basis decreased the allocation of resources to the activities I and II more than the control group. This incongruous behavior is predicted by the theory and it suggests that the participants have given up working for the purpose for which they were hired, prioritizing the maximization of their benefits, even with the prospect of negatively affecting the future performance of the store.

In summary, the results indicate that, even being aware that their experimental task was allocating in an optimal way the budget to the two activities in order to maximize the NPV in future cash flows of the store, the participants encouraged having contracts linked to contemporary performance measurement as a basis acted opportunistically, prioritizing the increase of their wealth at the expense of the contracted goal. The same did not occur with the parti- cipants who were rewarded on the basis of contracts linked to forward-looking performance measurement, who started striving more to allocate in a optimal way the resources, increasing investments in the activities I and II.

Due to the fact it is an incongruous performance measurement, the subjects linked to the book profit for the period focused their attention to short-term actions, giving up on investment alternatives with a positive NPV. However, in the presence of the horizon problem, economic profit was the only motivation to those showing a congruous behavior, as it induced increase in the allocation of resources to activities in order to improve the performance of stores in the long run. These findings provide support for non-rejection of the hypotheses $\mathbf{H 1}$ and $\mathbf{H} \mathbf{2}$.

Furthermore, when analyzing the performance of subjects to fulfill the task, expressed by the number of times that, on average, each participant managed to identify the optimal value of investments in the activities I and II before and after treatment, it was observed that the treatment groups had their performance affected by the incentive contract type, as displayed in tables 6,7 , and 8 , which show, respectively, the measurement of this variable, the results of non-parametric ${ }^{5}$ Mann-Whitney test, related to the comparison of difference in differences between the groups (within each treatment group compared to the difference within the control group) and Wilcoxon test, related to the comparison before and after within each group.

Number of times that the optimal investment value was identified before and after treatment

\begin{tabular}{|c|c|c|c|c|c|c|}
\hline \multirow{2}{*}{ VARIABLE } & \multicolumn{2}{|c|}{ BOOK } & \multicolumn{2}{|c|}{ ECONOMIC } & \multicolumn{2}{|c|}{ FIXED } \\
\hline & Before & After & Before & After & Before & After \\
\hline Number of times that the optimal investment value was identified & 1.92 & 1.04 & 1.52 & 2.60 & 1.19 & 1.50 \\
\hline
\end{tabular}

Note: BOOK represents the group linked to book profit before and after treatment, ECONOMIC represents the group linked to economic profit before and after treatment, and FIXED represents the control group.

Source: Prepared by the author.

Table 7 Results of the Mann-Whitney test for independent samples - control group $\times$ treatment group

\begin{tabular}{lcc}
\hline Statistics & Book $\times$ Control & Economic $\times$ Control \\
\hline Mann-Whitney U & 173.000 & 125.000 \\
Wilcoxon W & 498.000 & 450.000 \\
Z & -2.968 & -3.709 \\
P value (two-tailed) & 0.003 & 0.000 \\
\hline
\end{tabular}

Note: The result refers to the difference in differences of average values between the control group and the treatment group in relation to the measurement of the number of times the participant managed to identify the optimal investment value.

Source: Prepared by the author.

Table 8

Wilcoxon test result for dependent samples - within the groups

\begin{tabular}{lccc}
\hline Statistics & BOOK & ECONOMICO & FIXED \\
\hline$Z$ & -2.588 & -2.404 & -1.734 \\
P value (two-tailed) & 0.01 & 0.02 & 0.08 \\
\hline
\end{tabular}

Notes: (i) the test was performed by comparing, within the groups, the situation before and after treatment; (ii) the analysis was conducted considering a $5 \%$ significance level; (iii) BOOK represents the treatment group linked to book profit before and after treatment, ECONOMIC represents the treatment group linked to economic profit before and after treatment, and FIXED represents the control group before and after treatment.

Source: Prepared by the author.

The results in Table 8 clearly show the best performance in the treatment group linked to economic profit. It is worth noticing that, by considering a $5 \%$ level of sig- nificance, only the control group showed no significant difference between before and after $(p=0.08)$. 
The assessment of the number of times the participant managed to identify the optimal investment level is useful to measure the quality of decisions, because it corresponds to the result of the combination of effort intensity and the strategy used in the investment decision-making process.

Overall, the research findings consistently register that, as predicted by the economic theory, monetary incentive influences on the economic behavior of individuals. In the experiment, participants' actions suggest that, overall, they acted in order to maximize their earnings, even if it required behaving opportunistically. In the contract linked to book profit for the period, the participants gave up on fulfilling the task of maximizing future cash flow and acted according to their own interest to increase their compensation.

These results become more consistent when contrasted with the participants from the treatment group linked to economic profit. These subjects tried to comply with the contract as established, increasing investments to try to maximizing the future cash flow of the company. However, it is likely they have done so not by being effectively engaged with the objectives set for them, but because they were acting according to their own interest, seeking to maximize their compensation, and the only way to do it might be striving as hard as possible to fulfilling the task. Whereas the economic profit is a consistent performance measurement, the subjects linked to this forward-looking performance measurement could only maximize their earnings by maximizing the net future cash flow of the store, even facing the horizon problem. Thus, it was expected that the effort increases along with performance measurement.

Another significant aspect that is worth observing is the fact that when comparing the results of the control group to those of the treatment group linked to book profit, the coefficient of the variable $\boldsymbol{D} \boldsymbol{t}$ (which indicates the marginal effect on the variable under study in relation to the control group after experimental manipulation) against the value of the coefficient of the variable $\boldsymbol{B o o} \boldsymbol{k}^{\star} \boldsymbol{D} \boldsymbol{t}$ (which represents the marginal effect of treatment on the variable under study for the treatment group linked to book profit), it is observed that the control group obtained a better performance, because it increased investment in long-term activities, while the treatment group linked to the net profit for the period decreased it (beta $1,369.23$ with $p$ value 0.2654 , against a beta $-4,121.23$, with $\mathrm{p}$ value 0.0000 in the marginal effect of treatment).

According to Holmström and Milgrom (1991), this phenomenon may be associated with the fact that in a multi-task environment, where there are two equally important substitute actions to the principal, the agent will focus her/ his efforts on what is being measured and encouraged. This implies that the efforts will be consistent only with the goals of the principal if the performance on the task is rewarded having an undistorted measurement as a basis. If monetary incentive is provided having a distorted performance measurement as a basis, the authors conclude that it is preferable to compensate agents having a fixed remuneration as a basis, because in this case, the contract would be more cost-effective from the principal's viewpoint and it would avoid distortion in the allocation of effort.

Therefore, in the context of the experiment, the agency cost was lower when the participants were given a fixed compensation instead of a variable compensation contingent on performance, when performance measurement was contemporary book profit. This aspect serves to the purpose of reinforcing the idea that the success of the incentive system depends on how performance is measured and rewarded.

\subsection{Non-parametric test.}

To check the robustness of regression estimate, we performed a non-parametric test based on the difference in differences. The idea was comparing the average difference between the groups as independent sample pairs (control group versus treatment group). With this intent, the Mann-Whitney test was used. Tables 9 and 10 show the results of statistical tests.

\begin{tabular}{cc}
\hline Statistics & Variable (Invest) \\
\hline Mann-Whitney U & $6,660.00$ \\
Wilcoxon W & $14,535.00$ \\
Z & -2.49 \\
P value (two-tailed) & 0.01 \\
\hline
\end{tabular}

Note: The result refers to the difference in differences of the average values between the control group and the treatment group linked to the book profit. Source: Prepared by the author. Statistics of the Mann-Whitney test for difference in average values - control group x treatment group 2 (economic profit)

\begin{tabular}{cc}
\hline Statistics & Variable (Invest) \\
\hline Mann-Whitney U & $4,960.00$ \\
Wilcoxon W & $12,835.00$ \\
Z & -5.00 \\
P value (two-tailed) & 0.00 \\
\hline
\end{tabular}

Note: The result refers to the difference of the average values between the control group and the treatment group linked to economic profit. Source: Prepared by the author. 
As observed in tables 9 and 10, the tests showed statistical significance for alpha equal to 0.05 ( $p$ values 0.01 and 0.00 for the treatment groups 1 and 2, respectively). This result is consistent with that shown in Table 5. Together, the findings provide robustness to regression estimates, because they indicate that monetary incentive had an effect on participants' behavior regarding resource allocation decisions in the activities I and II, suggesting that the treatment had the expected effect on both groups.

\section{CONCLUSION}

This paper compared the use of forward-looking (economic profit) and contemporary performance measurement (net profit for the period) in incentive contracts in the presence of the horizon problem and it experimentally assessed how such measurements influence on the commitment of individuals to long-term goals. The results showed that, in the context of the experiment conducted, only the participants encouraged having forward-looking measurement as a basis acted congruently with the long-term goal established in the experimental task (maximizing the NPV in future cash flows of the company).

As registered, the marginal effect of monetary incentive was statistically significant on the efforts of individuals, and we identified support for both hypotheses. So, the main result of this study suggests that the use of forward-looking performance measurement helps mitigating managerial myopia. The direct implication of this is that incorporating it to contracts motivates agents to act more consistently with the long-term goals set, even when they have a short-term horizon in the job.

On the other hand, in the contract linked to contemporary performance measurement (net profit for the period), the participants gave up on fulfilling the task according to the contract (maximizing the NPV in future cash flows) and they acted in search of their own interest in order to increase their compensation, leaving investment decisions with positive NPV. The study registered that, when encouragement was provided in contemporary measurement, even being aware that the goal was maximizing the long-term return, the participants preferred to act in a myopic way, focusing their efforts on short-term results.

Our results show that, when comparing the two treatment groups and the control group, it is clear that the benefits of monetary incentive linked to performance depend on contract type, performance measurement, and the circumstances under which the contract is established, reinforcing the idea that contemporary metrics, such as book profit or any derivation of it, are inadequate to encourage a consistent behavior of agents if they have a short-term horizon in the job. As pointed out by previous studies, this performance measurement leads to a myopic behavior.

These results are supported by the economic theory and they suggest that the participants acted rationally, seeking to maximize their compensation. This took place because the agent is maximizing wealth and she/ he sees disutility in relation to the effort. So, she/he is willing to work harder only if the marginal gain of her/ his effort is greater than marginal cost. However, if monetarily rewarded having her/his performance as a basis, she/he will act rationally, in order to maximize wealth. As a result, she/he will aim efforts to where performance is rewarded differentially, and this action will be compatible with the goals of the principal only if performance measurement is congruent.

If the goal is making the agent aim her/his effort at long-term actions, economic profit is a congruent performance measurement, because, to be rewarded based on this metric, the agents start taking advantage of future benefits expected from their current decisions simultaneously. Thus, it matters little whether they will be in the job when the results actually come true. Moreover, in the specific case of the situation where the agent has a short-term hope, the contract does not impose any risk to her/him. The principal will fully support her/him and in return it has agent's commitment to long-term actions that create value for the company. As the principal can diversify its risk through other investment alternatives, economic profit can be an optimal solution to establish the contract.

Overall, the set of findings is consistent with those reported in previous studies and it helps to understanding how certain properties of incentive systems affect the individuals' economic behavior. Thus, this research, by providing new evidence of the inadequacy of formulating incentive contracts based on incongruent performance measures, contributes to extend the literature on the theme.

\section{References}

Barker, V. B., \& Mueller, G. C. (2002). CEO characteristics and firm R \& D spending. Management Science, 48, 782-801.

Berger, L. A. (2009). How incentive contracts and task complexity influence and facilitate long-term performance (Tese de Doutorado). University of Waterloo, Waterloo.

Cameron, A. C., \& Trivedi, P. K. (2005). Microeconometrics: methods and applications. Cambridge, MA: Cambridge University Press.

Cheng, S. (2004). R \& D expenditures and CEO compensation. The Accounting Review, 79, 305-328.

Chow, C. W. (1983). The effects of job standard tightness and compensation scheme on performance: an exploration of linkages. The Accounting Review, 58(4), 667-685. 
Dechow, P. M., \& Sloan, R. G. (1991). Executive incentives and the horizon problem: an empirical investigation. Journal of Accounting \& Economics, 14(1), 51-89.

Denison, C. A., Farrell, A. M., \& Jackson, K. E. (2012). Managers' incorporation of the value of real options into their long-term investment decisions: an experimental investigation. Contemporary Accounting Research, 29, 590-620.

Dikolli, S. S. (2001). Agent employment horizons and contracting demand for forward-looking performance measures. Journal of Accounting Research, 39(3), 481-494.

Dikolli, S. S., \& Vaysman, I. (2006). Contracting on the stock price and forward-looking performance measures. European Accounting Review, 15(4), 445-464.

Farrell, A. M., Kadous, K., \& Towry, K. L. (2008). Contracting on contemporaneous vs. forward-looking measures: an experimental investigation. Contemporary Accounting Research, 25(3), 773-802.

Feltham, G. A., \& Xie; J. (1994). Performance measure congruity and diversity in multi-task principal/agent relations. The Accounting Review, 69(3), 429-453.

Gibbons, R., \& Murphy, K. J. (1992). Does executive compensation affect investment? Journal of Applied Corporate Finance, 5, 99-109.

Holmström, B., \& Milgrom, P. (1991). Multitask principalagent analyses: incentive contracts, asset ownership, and job design. Journal of Law, Economics and Organizations, 7, 24-52.

Huang, R. (2006). Value creation, performance evaluation and managerial decisions on SG \& A expenditure (Tese de Doutorado). University of Texas, Dallas.

Kelly, K. (2007). Feedback and incentives on non-financial value drivers: effects on managerial decision making. Contemporary Accaunting Research, 24(2), 523-556

Matějka, M., Merchant, K. A., \& Van der Stede, W. A. (2009). Employment horizon and the choice of performance measures: empirical evidence from annual bonus plans of loss-making entities. Management Science, 55(6), 890-905
Mauldin, E. G. (1997). Decision aids and the design of incentive compensation contracts: an experimental study of self-selection and effort effects (Tese de Doutorado). University of Nebraska; Lincoln.

Narayanan, M. (1985). Managerial incentives for short-term results. Journal of Finance, 40, 69-84.

Naveen, L. (2006). Organizational complexity and succession planning. The Journal of Financial and Quantitative Analysis, 41(3), 661-683.

Schotter, A., \& Weigelt, K. (1992). Behavioral consequences of corporate incentives and long-term bonuses: an experimental study. Management Science, 38(9), 1280-1298.

Sedatole, K. L., Kulp, S. C., \& Dikolli, S. S. (2003). The role of CEO and investor horizons in the contracting use of forward-looking performance measures (Harvard NOM Working Paper n. 03-35). Cambridge, MA: Harvard University.

Sprinkle, G. B. (2000). The effect of incëntive contracts on learning and performance. The Accounting Review, 75(3), 299-326.

Tyler, M. L. (1995). The impact of CEO compensation and CEO horizon on a firm's discretionary research and development expenditures (Tese de Doutorado). Florida International University, Miami.

Wunsch, A. (1992). The effect of executive compensation policy on long-term investment expenditures of large corporations (Tese de Doutorado). University of Georgia, Athens.

$\mathrm{Xu}, \mathrm{J}$. (2009). $R \& D$ investment around CEO turnover (Tese de Doutorado). Boston University, Boston.

Correspondence Address:

Luis Paulo Guimarães dos Santos

Faculdade de Ciências Contábeis, Universidade Federal da Bahia

Avenida Reitor Miguel Calmon, s/n - CEP: 40110-903

Vale do Canela - Salvador - BA

E-mail: lupaufba@gmail.com 